\title{
QUEEN'S
UNIVERSITY
BELFAST
}

\section{iRhom2 and TNF: Partners or enemies?}

Badenes, M., \& Adrain, C. (2019). iRhom2 and TNF: Partners or enemies? Science Signaling, 12(605), [eaaz0444]. https://doi.org/10.1126/scisignal.aaz0444

\author{
Published in: \\ Science Signaling
}

\section{Document Version:}

Peer reviewed version

Queen's University Belfast - Research Portal:

Link to publication record in Queen's University Belfast Research Portal

\section{Publisher rights}

(C) 2019 American Association for the Advancement of Science. All rights reserved.

This work is made available online in accordance with the publisher's policies. Please refer to any applicable terms of use of the publisher.

\section{General rights}

Copyright for the publications made accessible via the Queen's University Belfast Research Portal is retained by the author(s) and / or other copyright owners and it is a condition of accessing these publications that users recognise and abide by the legal requirements associated with these rights.

Take down policy

The Research Portal is Queen's institutional repository that provides access to Queen's research output. Every effort has been made to ensure that content in the Research Portal does not infringe any person's rights, or applicable UK laws. If you discover content in the Research Portal that you believe breaches copyright or violates any law, please contact openaccess@qub.ac.uk. 


\title{
iRhom2 and TNF: partners or enemies?
}

Marina Badenes 1 and Colin Adrain 1,2

1Instituto Gulbenkian de Ciência (IGC), Oeiras, Portugal

2Centre for Cancer Research and Cell Biology, Queen's University Belfast, UK

Correspondence: mbadenes@igc.gulbenkian.pt, cadrain@igc.gulbenkian.pt, c.adrain@qub.ac.uk

\begin{abstract}
:
iRhom2 is an essential cofactor for ADAM17, the metalloprotease that sheds the apical proinflammatory cytokine Tumor Necrosis Factor (TNF), as well as its cognate TNF receptors (TNFRs) from the cell surface. In this issue of Science Signaling, Sundaram, et al. demonstrate a protective role for iRhom2 in promoting ADAM17 shedding of TNFRs. This reduces TNFR signaling in hepatic stellate cells, blocking their proliferation and activation, to prevent liver fibrosis.
\end{abstract}

BODY OF FOCUS: (1000 words)

ADAM17 (A Disintegrin And Metalloproteinase 17) (also called TACE, Tumor necrosis factorAlpha Converting Enzyme) is a pleiotropic protease that cleaves numerous membranetethered substrates, including the inflammatory cytokine TNF, and its receptors TNFRI and II (1). iRhom2 is an essential cofactor for ADAM17 that is highly expressed in immune cells (2). iRhom2 is required for multiple aspects of ADAM17 biology including: the trafficking of ADAM17 into the Golgi apparatus (where it undergoes a key proteolytic maturation step), the stimulation of ADAM17 activity on the cell surface (3), and the control of its proteolytic specificity (4). Notably, iRhom2 deletion protects mice from several inflammatory diseases, since ADAM17 activity is impaired and TNF secretion blocked in inflammatory cells $(2,5)$. The current assumption in the field is therefore that iRhom2 is pro-inflammatory. Surprisingly, in this issue (6), Sundaram and co-workers demonstrate that iRhom2 plays a protective role in a mouse model of inflammatory liver injury and fibrosis, by attenuating TNFR signaling.

Liver fibrosis develops as a result of chronic liver injury and can lead to liver cirrhosis and eventually to hepatocellular carcinoma. During liver injury, the release of inflammatory mediators, such as TNF and IL-1, activate NFkB to promote the proliferation of a normally dormant population of cells called hepatic stellate cells (HSC) (7). This triggers the proliferation and differentiation of HSC into pro-fibrotic myofibroblasts, which secrete collagen, promoting liver fibrosis (8). 
The authors of the present study found that cirrhotic human patients, and mice exposed to a model of liver fibrosis triggered by bile duct ligation (BDL), show increased circulating levels of TNFRI and II and increased iRhom2 mRNA expression in the liver. Interrogating this phenomenon further, ex vivo experiments with murine HSCs showed that iRhom2 is required for the shedding of both TNFRI and II. Consistent with this, in mice subjected to BDL, deletion of iRhom2 increased TNF signaling in the liver, presumably by blocking the shedding of TNFRs. This, in turn, was associated with HSC proliferation and fibrosis, potentially mediated by augmented TNFRI signaling. Consistent with this hypothesis, treatment of iRhom2 KO mice with the TNF inhibitor Etanercept blocked HSC proliferation and ameliorated liver fibrosis. The authors conclude that following BDL, iRhom2 expression may increase in HSCs, augmenting ADAM17 activity. The net result is shedding of TNFRs to dampen TNF signaling, preventing the proliferation of HSCs and liver fibrosis development, as illustrated in Fig. 1. This reveals an interesting scenario whereby iRhom2 attenuates the flux through an inflammatory signaling pathway to limit over-activation of tissue repair pathways that could lead to fibrosis.

As TNFRI and II can exert distinct biological outcomes, an obvious question concerns which TNFR is responsible for promoting the NFkB-dependent signaling pathways that make HSCs pro-fibrogenic. Although Sundaram and colleagues showed that HSCs release both TNRFI and II in an iRhom2-dependent manner, notably, when stimulated with TNF to mimic an inflammatory environment, TNFRII was preferentially cleaved. Interestingly, this suggests a model whereby TNFRII is shed as a decoy receptor, preventing TNF signaling through TNFRI. Notably, Etanercept is an engineered soluble form of TNFRII and this is its mode of action.

These data are consistent with previous studies that demonstrated a requirement for TNFRI, but not TNFRII, in protection from BDL-triggered fibrosis (7). Notably, TNFRI activation can affect fibrogenesis in several ways, such as inducing the remodeling of the extracellular matrix by promoting the production of matrix metalloproteinase-9 (MMP9) via activation of NF$\mathrm{KB}$ pathway (7). Therefore, the effects of iRhom2 deletion observed in the current paper can probably be attributed to TNFRI signaling.

What this work highlights more generally is that iRhoms/ADAM17 can impinge on TNF signaling in multiple ways, leading to sophisticated biological scenarios. First, the shedding of soluble TNF (sTNF), which is pro-inflammatory and preferentially activates TNFRI, could drive inflammation - the widely reported role of iRhom2. Second, the shedding of TNFRI and/or II could attenuate TNF signaling by blocking signal reception in cells with reduced TNFR levels, reducing signal flux. Alternatively, soluble TNFRs could act as a diffusible soluble sink for sTNF, blocking signaling in a non-cell-autonomous manner. Finally, the failure to produce sTNF would result in the accumulation of membrane tethered TNF (mTNF), which acts 
preferentially on TNFRII (9), eliciting distinct biological outcomes from TNFRI (10). In the latter case, iRhoms, rather than tuning signaling flux, could mediate a form of mode switching in the nature of TNF signaling.

Added to this already complicated scenario is the fact that mammals express a second iRhom paralog, iRhom1, with a distinct but partially overlapping tissue expression and a shared function with iRhom2 in ADAM17 regulation. Further layered on top of this, individual iRhoms (e.g. iRhom1 versus iRhom2) can govern ADAM17 substrate selectivity (4), providing another potential basis by which iRhoms can qualify the nature of TNF signaling by promoting the cleavage of a specific TNFR preferentially in a given tissue. Finally, iRhoms are regulated at the transcriptional and post-transcriptional levels, providing a sophisticated manner in which, dependent on the stimulus, or developmental context, the levels of an individual iRhom in a given tissue may be modulated to control signaling in a subtle, or indeed fundamental, manner.

A full understanding of how iRhom2 regulates TNF signaling has been a challenge, for the reasons illustrated above. Comparing the iRhom2 KO mice with the TNF, TNFRI and II mutants may not give sufficient clarity because of the complexity in the iRhom regulation of TNF signaling. In the case of the present paper, the deletion of iRhom2 (or ADAM17) specifically in HSCs would clarify if, in BDL-induced liver fibrosis, the protective effect of iRhom2 indeed acts upon HSCs, or whether other relevant cell types (e.g. hepatocytes, Kupffer cells, monocytes), which also express iRhom2, are involved. It would also be interesting to determine whether iRhom2 exerts a protective role in different models of liver fibrosis, and also in other TNF-mediated diseases. Nevertheless, this work reinforces the notion that iRhoms, in conjunction with ADAM17, can modulate TNF signaling in a highly sophisticated manner that can lead to signal attenuation, potentiation, or mode switching.

\section{Figure 1 Legend:}

During liver injury, Kupffer cells or hepatocytes secrete TNF, which promote iRhom2 mediated-ADAM17 maturation on hepatic stellate cells (HSCs). On the cell surface of WT HSCs, soluble TNF triggers ADAM17 to preferentially cleave TNFRII, allowing the latter to act as a soluble/diffusible sink to sequester TNF ligand, preventing TNFRI signaling. In the absence of this iRhom2-dependent inhibitory mechanism, TNF binds to TNFRI to promote HSC proliferation and activation to become myofibroblasts, leading to fibrosis.

\section{REFERENCES}


1. J. Scheller, A. Chalaris, C. Garbers, S. Rose-John, ADAM17: a molecular switch to control inflammation and tissue regeneration. Trends Immunol 32, 380-387 (2011); published online EpubAug (10.1016/j.it.2011.05.005).

2. C. Adrain, M. Zettl, Y. Christova, N. Taylor, M. Freeman, Tumor Necrosis Factor Signaling Requires iRhom2 to Promote Trafficking and Activation of TACE. Science 335, 225-228 (2012); published online EpubJan 13 (10.1126/science.1214400).

3. M. Cavadas, I. Oikonomidi, C. J. Gaspar, E. Burbridge, M. Badenes, I. Felix, A. Bolado, T. Hu, A. Bileck, C. Gerner, P. M. Domingos, A. von Kriegsheim, C. Adrain, Phosphorylation of iRhom2 Controls Stimulated Proteolytic Shedding by the Metalloprotease ADAM17/TACE. Cell Rep 21, 745-757 (2017); published online EpubOct 17 (10.1016/j.celrep.2017.09.074).

4. T. Maretzky, D. R. Mcllwain, P. D. Issuree, X. Li, J. Malapeira, S. Amin, P. A. Lang, T. W. Mak, C. P. Blobel, iRhom2 controls the substrate selectivity of stimulated ADAM17dependent ectodomain shedding. Proceedings of the National Academy of Sciences of the United States of America 110, 11433-11438 (2013); published online EpubJul 09 (10.1073/pnas.1302553110).

5. P. D. A. Issuree, T. Maretzky, D. R. Mcllwain, S. Monette, X. P. Qing, P. A. Lang, S. L. Swendeman, K. H. Park-Min, N. Binder, G. D. Kalliolias, A. Yarilina, K. Horiuchi, L. B. Ivashkiv, T. W. Mak, J. E. Salmon, C. P. Blobel, iRHOM2 is a critical pathogenic mediator of inflammatory arthritis. Journal of Clinical Investigation 123, 928-932 (2013); published online EpubFeb (10.1172/JCl66168).

6. Space reserved for Sundaram et al., this issue.

7. N. Tarrats, A. Moles, A. Morales, C. Garcia-Ruiz, J. C. Fernandez-Checa, M. Mari, Critical role of tumor necrosis factor receptor 1 , but not 2, in hepatic stellate cell proliferation, extracellular matrix remodeling, and liver fibrogenesis. Hepatology 54, 319-327 (2011); published online EpubJul (10.1002/hep.24388).

8. C. Y. Zhang, W. G. Yuan, P. He, J. H. Lei, C. X. Wang, Liver fibrosis and hepatic stellate cells: Etiology, pathological hallmarks and therapeutic targets. World journal of gastroenterology : WJG 22, 10512-10522 (2016); published online EpubDec 28 (10.3748/wjg.v22.i48.10512).

9. M. Grell, E. Douni, H. Wajant, M. Lohden, M. Clauss, B. Maxeiner, S. Georgopoulos, W. Lesslauer, G. Kollias, K. Pfizenmaier, P. Scheurich, The transmembrane form of tumor necrosis factor is the prime activating ligand of the $80 \mathrm{kDa}$ tumor necrosis factor receptor. Cell 83, 793-802 (1995); published online EpubDec 1 (10.1016/00928674(95)90192-2).

10. T. Hehlgans, K. Pfeffer, The intriguing biology of the tumour necrosis factor/tumour necrosis factor receptor superfamily: players, rules and the games. Immunology 115, 1-20 (2005); published online EpubMay (10.1111/j.1365-2567.2005.02143.x). 


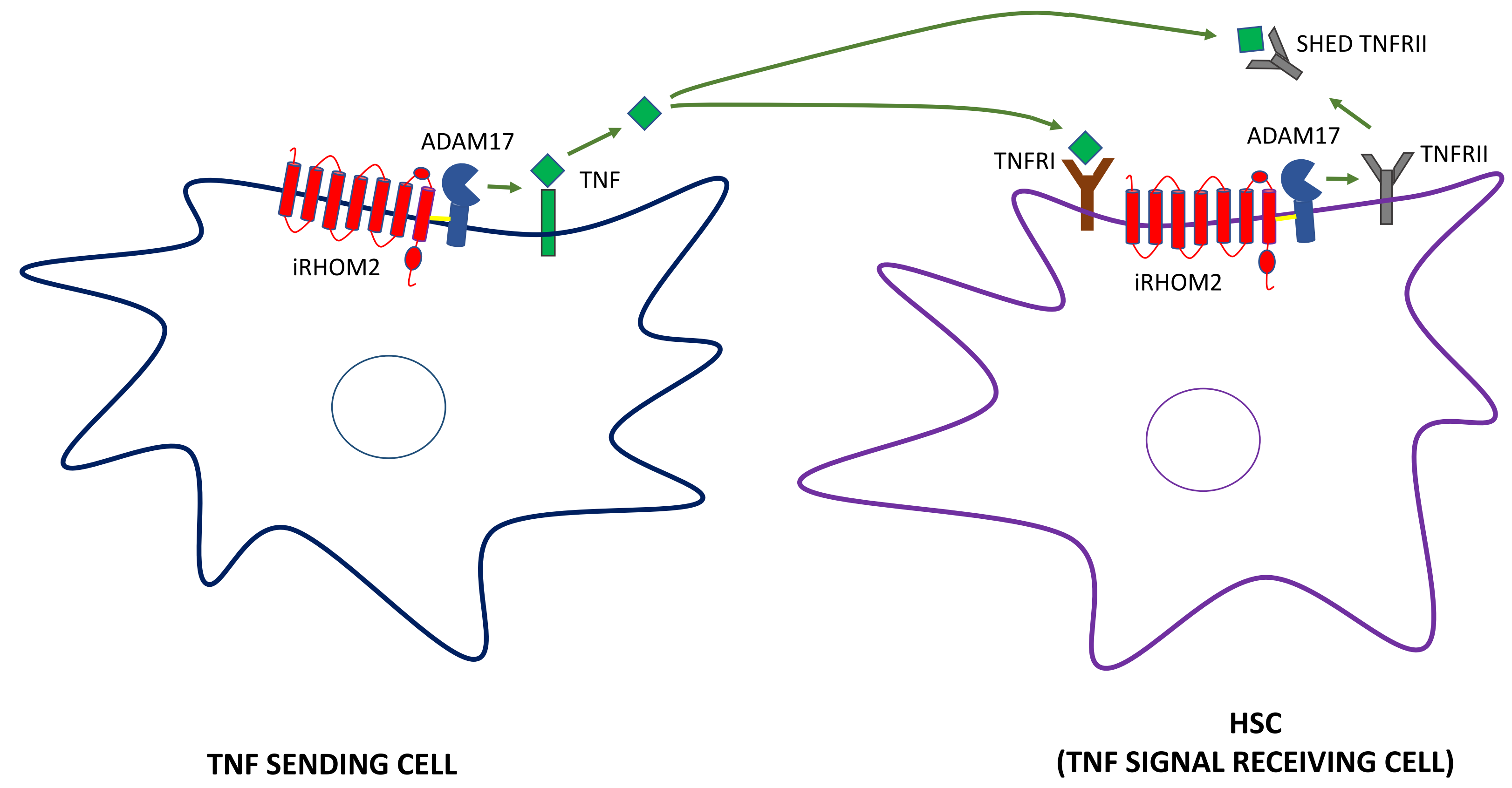

